\title{
Kemampuan Siswa dalam Pemecahan Masalah Matematika dengan Strategi Heuristik
}

\author{
Hardi Tambunan $^{1}$, Bornok Sinaga ${ }^{2}$, Tatag Yuli Eko Siswono ${ }^{3}$ \\ ${ }^{1}$ Universitas HKBP Nommensen, Medan. ${ }^{2}$ Universitas Negeri Medan ${ }^{2},{ }^{3}$ Universitas Negeri Surabaya \\ Correspondence: ${ }^{1}$ tambunhardi@gmail.com
}

\begin{abstract}
The purpose of this study is to describe the ability of students in solving mathematical problems after learning with heuristic strategies. This quasi-experimental study uses a randomize control group pretest-posttest design. The experimental group is a group of students who are taught with heuristic strategies, and the control group is students who are taught with conventional approaches. The population is 280 high school grade $X$ students. Samples $n=74$ for the experimental class, and $n=72$ for the control class were taken through cluster random sampling. Based on data analysis through analysis of covariant, the results obtained that learning with heuristic strategies are better than conventional approaches to students' ability to solve mathematical problems.
\end{abstract}

Keyword: Heuristic strategy, ability, problem solving

\begin{abstract}
Abstrak
Tujuan penelitian ini adalah untuk mendeskripsikan kemampuan siswa dalam pemecahan masalah matematika setelah pembelajaran dengan strategi heuristik. Penelitian quasi eksperimen ini menggunakan randomize control group pretest-posttest design. Kelompok eksperimen yaitu kelompok siswa yang diajar dengan strategi heuristic, dan kelompok control adalah siswa yang diajar dengan pendekatan konvensional. Populasi sebanyak 280 siswa kelas X SMA. Sampel $\mathrm{n}=74$ untuk kelas eksperimen, dan $\mathrm{n}=72$ untuk kelas control diambil melalui cluster random sampling. Berdasarkan analisis data melalui analysis of covariant diperoleh hasil bahwa pembelajaran dengan strategi heuristik lebih baik daripada pendekatan konvensional terhadap kemampuan siswa dalam memecahkan masalah matematika.
\end{abstract}

Kata Kunci: Strategi heuristik, kemampuan, pemecahan masalah

\section{Pendahuluan}

Pemecahan masalah masih isu penting dalam pembelajaran matematika sekolah. Pemecahan masalah berperan penting dalam pendidikan matematika agar siswa dapat berlatih dan mengintegrasikan konsep-konsep, teorema-teorema dan keterampilan yang telah dipelajari (Hudojo, 2005), memperoleh cara berpikir yang baik, tekun, keinginan yang tinggi, dan percaya diri (Turmudi, 2008), dan meningkatkan kemampuan matematis siswa (NCTM, 2010).

Belajar matematika berarti mempelajari suatu masalah, yaitu suatu pernyataan atau pertanyaan dalam matematika untuk diselesaikan (Baroody, 1993; Tambunan, 1999). Masalah dalam matematika adalah suatu soal cerita yang tidak ada aturan tertentu untuk segera dapat digunakan 
menyelesaikannya (Tambunan, 2014). Oleh karena itu, pembelajaran pemecahan masalah matematika memerlukan pendekatan khusus yang dapat mempermudah pemecah untuk menyelesaikan masalah yang ada. Pendekatan pemecahan masalah mempengaruhi kemampuan siswa (Perveen, 2010; Sriasih, Syahruddin, \& Japa, 2014), mempermudah siswa untuk memecahkan masalah yang sulit (Oztruk \& Guven, 2016), dan strategi pemecahan masalah mempengaruhi kemampuan pemecahan masalah (Tambunan, 2019).

Banyak pendekatan yang dapat digunakan untuk pemecahan masalah matematika. Supaya lebih mudah melakukan pemecahan masalah, maka dapat dilakukan suatu strategi. Menurut Yamin (2013) bahwa strategi adalah suatu rangkaian langkah-langkah untuk mencapai tujuan, dan suatu rancangan kegiatan untuk mencapai tujuan pendidikan (Ngalimun, 2014). Suatu strategi dengan memberikan heuristik (arahan) dalam bentuk pernyataan, perintah atau pertanyaan terhadap setiap langkah pemecahan masalah disebut sebagai strategi heuristik (Tambunan, 1999).

Terkait dengan dampak heuristic dalam pemecahan masalah, beberapa hasil penelitian menunjukkan bahwa heuristik efektif digunakan dalam pemecahan masalah (Chavez, 2007). Hasil penelitian Hoona (2013) menunjukkan bahwa dengan pendekatan heuristic, siswa dapat melakukan pemecahan masalah matematika dengan baik. Heuristik memberikan hasil positif terhadap kemampuan pemecahan masalah (Novotna, 2014), dan strategi heuristik berdampak terhadap kemampuan siswa dalam pemecahan masalah matematika (Tambunan, 2018).

Bila dibandingkan dua pendekatan dalam pemecahan masalah, bahwa pemberian heuristic lebih baik daripada konvensional terhadap prestasi siswa dalam pemecahan masalah (Abonyi, 2014), dan tingkat prestasi siswa yang diajar dengan metode pemecahan masalah berbeda dengan metode pengajaran konvensional (Behlol, Akbar, \& Sehrish, 2018). Sehingga menjadi pertanyaan adalah apakah strategi heuristik lebih baik daripada pendekatan konvensional (tanpa heuristik) untuk membangun kemampuan siswa dalam pemecahan masalah matematika?.

\section{Strategi Heuristik}

Strategi adalah suatu usaha kegiatan, rancangan, pendekatan, dan rangkaian langkah-langkah yang dilakukan oleh guru untuk mencapai suatu tujuan pendidikan (Yamin, 2013; Ngalimun, 2014). Pelaksanaan strategi pembelajaran dapat diberikan beberapa heuristik penting untuk mempermudah siswa memahami materi pelajaran. Heuristics as an adjective, means "serving to discover"(Polya, 1973 ). Heuristics are general suggestion that help an individual to make progress toward its solution (Schoenfeld, 1985). Heuristik adalah suatu petunjuk yang dapat mengarahkaan pemecah masalah untuk menemukan suatu solusi dari masalah (Tambunan, 2014).

Polya (1973) menyatakan empat tahap dalam pembelajaran pemecahan masalah, yaitu (1) memahami masalah, (2) merencanakan pemecahan, (3) menyelesaikan model, dan (4) memeriksa kembali. Suatu strategi dengan memberikan heuristik dalam bentuk pernyataan, perintah atau 
pertanyaan terhadap keempat tahap dan langkah pemecahan masalah disebut sebagai strategi heuristik (Tambunan, 1999). Operasional strategi heuristik dalam pemecahan masalah secara ringkas dapat dilakukan sebagai berikut. Tahap pertama, memahami masalah. Pada tahap ini, beberapa langkah yang harus dilakukan. Langkah pertama adalah menyatakan masalah dengan kata kata sendiri. Kemampuan menyatakan masalah dengan kata kata sendiri menunjukkan sudah memahami permasalahan yang ada, sehingga akan mudah menyelesaikan masalah yang ada. Oleh karena itu heuristik untuk menuntun siswa dapat menyatakan masalah dengan kata-kata sendiri misalnya; baca soal masalah, apa yang terdapat dalam soal ?, nyatakan masalah dengan katakatamu sendiri, atau tulis kembali soal tersebut sesuai kata katamu sendiri.

Langkah kedua, membuat ilustrasi dari masalah. Membuat ilustrasi dari masalah bermanfaat untuk memahami masalah sebenarnya, sehingga heuristik yang diberikan seperti; buatlah ilustrasi dari masalah (sketsa gambar, pola, tabel, daftar, atau lainnya). Langkah ketiga adalah menentukan apa yang ditanya. Heuristik yang diberikan seperti; apa yang ditanya dalam soal ?. Langkah keempat adalah memahami informasi yang ada. Heuristik yang diberikan seperti "apa yang diketahui ?. apakah yang diketahui sudah cukup untuk menjawab yang ditanya ?, informasi tambahan apa yang diperlukan?.

Tahap kedua, merencanakan pemecahan. Pada tahap ini mengarahkan siswa agar dapat membuat model matematika dari masalah. Beberapa heuristik yang diberikan seperti; perhatikan ilustrasi, pikirkan hubungan yang diketahui dengan yang ditanya, bagaimana mencari yang ditanya ?, buatlah pemisalan dengan suatu perubah untuk yang diketahui dan ditanya, rumus apa yang dapat digunakan untuk menjawab yang ditanya ?, buatlah model matematika dari masalah ?.

Tahap ketiga, melaksanakan rencana penyelesaian. Heuristik yang dapat diberikan pada tahap ini seperti; selesaikan model matematika yang sudah dibuat, variabel apa yang sudah diketahui ?, variabel mana yang belum diketahui ?, apakah variabel itu yang akan dicari ?, cari dahulu variabel yang belum ada tetapi diperlukan di dalam penyelesaian model.

Tahap keempat adalah memeriksa kembali. Tahap ini pemecah diarahkan untuk memeriksa apakah langkah langkah yang dilakukan sudah benar, dan apakah hasil yang diperoleh sudah sesuai dengan yang ditanyakan dalam soal, sehingga heuristik yang dapat diberikan seperti; periksa, apakah langlah langkah pemecahan yang dilakukan sudah benar ?. Uji kembali hasil yang diperoleh, apakah hasilnya sudah benar?, tulis model matematika yang sudah dibuat, subsitusikan hasil yang diperoleh ke model matematika, apakah hasilnya sudah sama ?, apa kesimpulanmu ?. Heuristik lain dapat dilakukan sesuai dengan materi ajar, kondisi dan kemampuan intelektual individu sehingga siswa dapat memecahkan masalah dengan baik.

\section{Metode Penelitian}

Jenis penelitian ini adalah quasi eksperimen. Rancangan penelitian menggunakan randomize control group pretest-posttest design. Kelompok eksperimen yaitu kelompok siswa yang diajar 
dengan strategi heuristik, dan kelompok kontrol adalah siswa yang diajar dengan pendekatan konvensiona.

Populasi dalam penelitian ini sebanyak 280 siswa kelas 10 yang berasal dari dua sekolah swasta di Medan. Sampel diambil 1 kelas dari setiap sekolah melalui cluster random sampling. Jumlah siswa kelas eksperimen sebanyak 74 orang $(n=74)$, dan sebanyak 72 orang $(n=72)$ untuk kelas control.

Analisis data hasil pretest dan post test soal bentuk uraian digunakan untuk menguji hipotesis penelitian yang dinyatakan dalam $\mathrm{H}_{0}$ dan $\mathrm{H}_{1}$, yaitu:

$\mathrm{H}_{0}: \mu_{1}=\mu_{2}$ : Kemampuan siswa dalam pemecahan masalah yang diajar dengan strategi heuristik sama dengan yang diajar dengan pendekatan konvensional

$\mathrm{H}_{1}: \mu_{1}>\mu_{2}$ : Kemampuan siswa dalam pemecahan masalah yang diajar dengan strategi heuristik lebih baik daripada yang diajar dengan pendekatan konvensional

Karena data yang dianalisis terdiri dari hasil pretest sebagai kovarian dan satu variabel terikat untuk kelas eksperimen dan kontrol, maka data dianalisis dengan analysis of covariance dengan rumus $\mathrm{F}^{*}=\frac{\operatorname{MSTR}_{(a d j)}}{\operatorname{MSE}_{(a d j)}}$ pada level significant 0.05 , dengan syarat koefisien model regresi harus signifikan, linier dan homogen (Neter dan Wasserman, 1974; Mann, 2011). Ketiga syarat tersebut terpenuhi dengan membandingkan nila $F_{\text {hitung }}\left(F^{*}\right)$ dengan nilai $F$ tabel. Model regresi adalah signifikan apabila $F^{*}>F_{(1-\alpha ; 1, n-2)}$, linier apabila $F^{*}<F_{(1-\alpha ; k-2, n-k)}$, dan homogen apabila $F^{*}<F_{(1-\alpha ; k-1, N-2 k)}$.

\section{Hasil Penelitian dan Pembahasan}

Sesuai dengan tujuan penelitian untuk mengetahui mana lebih baik diantara pembelajaran melalui strategi heuristik dengan pendekatan konvensional terhadap kemampuan siswa dalam pemecahan masalah matematika, maka ringkasan pengujian hipotesis penelitian diuraikan seperti berikut.

Berdasarkan analisis data, diperoleh model regresi untuk kelas eksperimen, yaitu $\mathrm{Y} 1=23.88+6.43 \mathrm{X} 1$, dan untuk kelas kontrol adalah $\mathrm{Y} 2=7.23+5.60 \mathrm{X} 2$. Selanjutnya, diuji keberartian koefisien regresi untuk mengetahui pengaruh kemampuan awal terhadap terhadap kemampuan pemecah masalah.

Hasil analisis data pada tingkat signifikansi 0.05 untuk kelas eksperimen diperoleh $\mathrm{F}_{(0.95 ; 1,72)}=3.976$, dan $\mathrm{F}^{*}$ hitung sebesar 12.332 atau $\mathrm{F}^{*}=12.332$, berarti $\mathrm{F}^{*}=12.332>\mathrm{F}_{(0.95 ; 1,72)}=3.976$. Analisis data kelas kontrol diperoleh nilai $F^{*}$ hitung atau $F^{*}=9.436$, jadi $F^{*}=9.436>F_{(0.95 ; 1,70)}=3.980$. Hal itu berarti, ada pengaruh pengaruh secara signifikan kemampuan awal terhadap terhadap kemampuan pemecahan masalah pada kelas eksperimen dan kontrol.

Kedua model regresi adalah linier, hal itu ditunjukkan bahwa pada tingkat signifikansi 0.05 diperoleh nilai $\mathrm{F}_{(0.95 ; 1,72)}=3.976$, hasil analisis untuk kelas eksperimen diperoleh nilai $\mathrm{F}^{*}=0.840$, berarti $F^{*}<F_{(0.95 ; 1,72)}$, dan untuk kelas kontrol diperoleh nilai $F^{*}=1.201$, dan $F_{(0.95 ; 1,70)}=3.98$, jadi $F^{*}<$ $\mathrm{F}_{(0.95 ; 1,70)}=3.98$. Uji homogenitas kedua model regrersi, diperoleh nilai $\mathrm{F}_{(0.95 ; 1,142)}=3,920$, dan nilai $\mathrm{F}^{*}$ 
hitung sebesar 0.094 atau $F^{*}=0.094$, jadi $F^{*}<F_{(0.95 ; 1,142)}$. Hal itu berarti kedua model adalah homogen. Karena ketiga syarat dipenuhi maka dapat dilanjutkan analysis of covariant.

Berdasarkan hasil uji hipotesis penelitian dengan analysis of covarian menunjukkan bahwa nilai $F^{*}=9.2534>F_{(0.95 ; 1,125)}=3.9128$, berarti hasil kelas eksperimen lebih baik daripada kelas control. Hal itu berarti pembelajaran melalui strategi heuristik lebih baik daripada pembelajaran melalui pendekatan saintifik terhadap kemampuan siswa dalam pemecahan masalah matematika. Ringkasan analysis of covariant untuk rancangan lengkap seperti dalam tabel 1 berikut.

Table 1. Summary of Analysis of Covariance

\begin{tabular}{|l|c|c|c|c|}
\hline \multirow{2}{*}{$\begin{array}{l}\text { Source of } \\
\text { Variation }\end{array}$} & \multicolumn{3}{|c|}{ Sums of Squares or Product } & \multirow{2}{*}{$\mathrm{df}$} \\
\cline { 2 - 4 } & $\mathrm{X}$ & $\mathrm{Y}$ & $\mathrm{XY}$ & \\
\hline Treatments & 0.0584 & 11181.1101 & 25.5606 & 1 \\
\hline Error & 34.0111 & 9190.8211 & 200.3563 & 144 \\
\hline Total & 34.0695 & 20371.9312 & 225.9169 & 145 \\
\hline $\begin{array}{l}\text { Source of } \\
\text { Variation }\end{array}$ & $\begin{array}{c}\text { Adjusted } \\
\mathrm{df}\end{array}$ & $\begin{array}{c}\text { Adjusted } \\
\text { Sum of Squares }\end{array}$ & $\begin{array}{c}\text { Adjusted } \\
\text { Mean Squares }\end{array}$ & \multirow{2}{*}{$\mathrm{F}^{*}$} \\
\hline Treatments & 1 & 1.9207 & 1.9207 & 9.2534 \\
\hline Error & 143 & 29.6835 & 0.2076 & - \\
\hline Total & 144 & 31.6043 & - & - \\
\hline
\end{tabular}

\section{Kesimpulan}

Banyak pendekatan yang sudah dikembangkan oleh para pakar pendidikan untuk digunakan dalam pemecahan masalah matematika. Terdapat empat tahap pemecahan masalah, yaitu memahami masalah, merencanakan penyelesaian, melaksanakan rencana penyelesaian, dan memeriksa kembali. Agar supaya lebih mudah melakukan pemecahan masalah maka dapat diberikan heuristik dalam bentuk pernyataan atau pertanyaan pada keempat tahap dan langkah pemecahan masalah tersebut, dan disebut sebagai strategi heuristik. Pembelajaran dengan strategi heuristik lebih baik daripada pendekatan konvensional terhadap kemampuan siswa dalam memecahkan masalah matematika.

\section{Referensi}

Abonyi, O. S., and Umeh, V. O. (2014). Effects of Heuristic Method of Teaching on Students' Achievement in Algebra. International Journal of Scientific \& Engineering Research, Volume 5, Issue 2, 1735-1740.

Baroody, A. J. (1993). Problem Solving. Reasoning, and Communicating K-8 (Helping Children Think Mathematically). New York: Macmillan Publishing Company.

Behlol, M. G., Akbar, R. A., \& Sehrish, H. (2018). Effectiveness of Problem Solving Method in Teaching Mathematics at Elementary Level. Bulletin of Education and Research, 40(1), 231244

Chavez, J. A. (2007). Enlivening Problems with Heuristics Through Learning Activities and Problem Solving (LAPS). Learning Science and Mathematics, SEAMEO RECSAM, Issue 2, $1-8$

Hoona, T.H., Kee, K. L., and Singh, P (2013). Learning Mathematics Using Heuristic Approach. Procedia - Social and Behavioral Sciences, 90. 862-869. 
Hudojo, H. (2005). Pengembangan Kurikulum Matematika dan Pelaksanaannya di Depan Kelas. Surabaya: Usaha Nasional.

Mann, P.S. (2011). Introductory Statistics. USA: Estern Connecticut State University.

NCTM. (2010). Why Is Teaching With Problem Solving Important to Student Learning?. 1-6.

Neter, J., \& Wasserman, W. (1974). Applied Linear Statistical Models. USA: Richard. D. Irwin, Inc

Ngalimun. (2014). Strategi dan Model Pembelajaran. Yogyakarta: Aswaja Presindo.

Novotná, J. et al. (2014). Problem Solving in School Mathematics Based on Heuristic Strategies. Journal on Efficiency and Responsibility in Education and Science, Vol. 7, No. 1, 1-6

Oztruk, T., \& Guven, B. (2016). Evaluating Students' Beliefs in Problem Solving Process: A Case Study. Eurasia Journal of Mathematics, Science \& Technology Education, 12(2), 411-429

Perveen, K. (2010). Effect Of The Problem Solving Approach on Academic Achievement of Students in Mathematics at the Secondary Level. Contemporary Issues In Education Research, 3 (3), 9-14

Polya, G. (1973). How To Solve It. New Jersey. Princeton

Schoenfeld, A. H. (1985). Mathematical Problem Solving. USA. Academic Press, Inc

Sriasih, N. W, Syahruddin., \& Japa, I.G.N (2014). Pengaruh Keterampilan Pemecahan Masalah Terhadap Hasil Belajar Matematika Siswa Kelas III SD Negeri 1 Banyuning. e-Journal Mimbar PGSD Universitas Pendidikan Ganesha Jurusan PGSD, 2(1), 1-10.

Tambunan, H. (1999). Kemampuan Siswa Menyelesaikan Soal Cerita Pokok Bahasan Trigonometri dengan Strategi Heuristik. (Unpublished Master Tesis). IKIP Surabaya

Tambunan, H. (2014). Strategi Heuristik dalam Pemecahan Matematika Sekolah. Jurnal Saintech. Vol. 6 , No. 4, 35-40

Tambunan, H. (2016). Mathematical Model for Mapping Students' Cognitive Capability. International Journal of Evaluation and Research in Education (IJERE), Vol.5, No.3, 221226

Tambunan, H. (2018). Impact of Heuristic Strategy on Students' Mathematics Ability in High Order Thinking. International Electronic Journal of Mathematics Education. Vol. 13, No. 3, 321-328

Tambunan, H. (2019). The Effectiveness of the Problem Solving Strategy and the Scientific Approach to Students' Mathematical Capabilities in High Order Thinking Skills. International Electronic Journal of Mathematics Education.Vol. 14, No. 2, 293-302

Tambunan, H., dan Naibaho, T. (2019). Performance of mathematics teachers to build students' high order thinking skills (HOTS). Journal of Education and Learning (EduLearn) Vol. 13, No. 1, February 2019, 111-117

Turmudi. (2008). Landasan Filsafat dan Teori Pembelajaran Berparadigma Eksploratif dan Investigatif. Jakarta: PT Leuser Cita Pustaka.

Yamin, M. (2013). Strategi dan Metode dalam Model Model Pembelajaran. Jakarta: Press Goup. 